\title{
Grammaticalized temporal categories, language specificity, and macroplanning in expository texts ${ }^{1}$
}

CHRISTIANE VON STUTTERHEIM, ABASSIA BOUHAOUS, MARY

CARROLL AND NATASHA SAHONENKO

Abstract

The linguistic knowledge which is brought to bear in carrying out a complex task such as a narrative or route directions has been at the centre of a series of studies on language-specific patterns in the organization of information for expression. Analyses of oral and written texts in German, Standard Arabic, and Russian show different patterns in macro-structural organization and macroplanning that correlate with grammatical features of the respective languages. The findings for expository texts present evidence for a hierarchy of factors in the organization of information that are linked to grammaticalized temporal categories and their role in guiding options in perspective taking and information organization at text level. We assume that inflectional categories function as a scaffold in organizing content for expression since concepts that have paved their way into the grammar of a language will have prominence in language use, given their obligatory status in associated domains of reference. Global planning principles allow the speaker or writer to integrate knowledge from different sources on a systematic basis and thus meet constraints with respect to text coherence without having to solve core issues for each sentence anew.

\section{Introduction}

Although the relation between language and thought has never been seriously called into question, and discussions on this topic can be traced back to Greek philosophy, the crucial question rests with the nature of this relation. Which aspects of language influence thought and in what way? One of the first to formulate a strong position on this issue was W. von Humboldt. Based on extensive comparative studies, he coined the notion of a 'sprachliche Weltansicht' which he describes as mediating between the external and internal world (cf. von Humboldt 1836-1839). Although Humboldt believes that people can 
acquire different views on the world by learning a new language, he retains a normative viewpoint in regarding a particular type of language (inflectional) as optimally suited for formulating thought. Radical interpretations of linguistic relativity consolidated the notion of linguistic determinism (cf. Lee 1996), a position which implies that speakers who have learned a given language not only develop language-specific conceptual structures, but are also bound by them, a view known as the Sapir-Whorf hypothesis.

The debate on the relationship between language and thought received new impetus in the areas of cognitive science, cultural anthropology, cognitive linguistics, as well as developmental psychology with the introduction of empirical tools that provide a window on cognitive processes. Following the hypothesis that semantic differences across languages may engender cognitive differences, studies from the field of cultural anthropology show that language influences the way in which the world is partitioned, whereby languagespecific encoding patterns can be seen to facilitate one type of mental representation while acting as a constraint on others - in line with the output modality (Gumperz and Levinson 1996; Lucy 1996; Levinson 2003, 2006; Gentner and Goldin-Meadow 2003). This contrasts with the position taken by researchers who assume that the cognitive basis for conceptualization and reasoning is universal. In this case cognitive differences engendered by language are viewed as possible variations without substantial consequences. Languages are viewed as a medium of expression along universal lines, since "Linguistic systems are merely the formal and expressive medium that speakers devise to describe their mental representations and manipulations of their reference world." (Li and Gleitman 2002: 23).

Studies on the relation between language and cognition in cognitive linguistics and developmental psychology have drawn attention in particular to the role of grammatical form in relation to cognition. In describing the possible relation of grammar to cognition Talmy (1988) proposed that grammar expresses a restricted set of general notions that make up the basic schematic framework for conceptual organization within the cognitive domain of language. The "set of grammatically specified notions collectively constitutes the fundamental conceptual structuring system of language" (Talmy 1988: 166). This view led to work which investigates both the unity across different languages, as well as their diversity, and what this entails (Talmy 2000; Evans and Levinson 2009). It was assumed that the child learns a particular 'framework for schematising experience' in acquiring the grammar of a particular language. This claim was made for cognitive representations that hold when thinking for speaking, i.e., when speakers are required to encode information in a specific linguistic system, and not necessarily when reasoning takes place outside linguistic tasks (cf. Slobin 1987, 1991, 1996; Berman and Slobin 1994). 
The present study deals with language-specific effects at the level of discourse, with a focus on the role of grammaticalized means in selecting and connecting information in text production. The existence of language-specific principles at text level becomes immediately evident when translating a text into another language. It is a common experience that translations cannot be conducted on a one to one basis, even if there are close solutions at sentence level; but these disappear in relevance when it comes to principles that underlie information flow, for example, and force the translator to leave certain facets unexpressed, or provide more information elsewhere. So what determines the flow of information and what makes information organization in one language differ from the pattern in another language, although language-external factors such as the content to be expressed or the communicative situation may be comparable? Previous research on this topic does not provide a clear-cut answer to these questions (cf. Moder and Martinovic-Zic 2004). A particular issue which still remains unsettled concerns the question in how far are the grounds of a structural nature and to what extent can they be attributed to rhetorical or stylistic conventions given with different cultures?

One way of isolating such factors is to collect data from languages which form part of a common cultural background but have different linguistic systems (cf. Pederson 1995). Another is to take different languages and cultural groups and keep relevant linguistic features constant. If grammaticalized meanings belong to the factors driving the coding options selected in language use, speakers of languages which share a similar grammatical profile in a given semantic domain should exhibit similar patterns of information structure, irrespective of cultural differences. This is the perspective adopted in the present crosslinguistic investigation of information structure at text level. The article is structured as follows: In order to introduce central theoretical notions and provide some background knowledge, we will take a brief look at what macrostructural planning implies (Section 2). This will be illustrated further by a brief summary of the findings for a previous crosslinguistic study on narrative texts (Section 3), which will provide the basis for formulating the central hypothesis with respect to our empirical investigation on language specificity in the construction of expository texts. The empirical study starts with a discussion on the text type 'expository text', and includes references to this rather undeveloped research field (Section 4). We then come to the description of the data base and key questions in the analysis which centre on the function of temporal concepts. In Section (5), which forms the main body of the paper, we present the results with respect to three aspects: 5.1 macrostructural organization of texts, 5.2 openings, 5.3 temporal reference. This is followed by a summary in (6) and in (7) we conclude by summarizing the evidence for language-specific effects in macrostructural planning of expository texts. 


\section{Macroplanning}

One of the well established assumptions in text linguistics (Antos et al. 2000) as well as psycholinguistics (cf. Levelt 1989) relates to the role of global planning principles that allow the speaker to deal with text coherence on the scale required. We assume that the integration of information from different semantic domains in language production is conducted on the basis of overarching principles that guide the decisions required at each relevant stage in the text production process. They enable the speaker to control information organization in goal-oriented terms and provide the means for selecting the appropriate verbal form, covering the following steps in message preparation:

- Segmentation

When considering what to say, complex static situations, for instance, have to be broken down into states or property predications, and complex dynamic situations into events or processes. Units of this kind are formed and extracted from a knowledge base that is not structured nor organized hierarchically in this form with respect to a given subject.

- Selection

Speakers select units for verbalization as well as the components by which they can be represented in propositional form. They form the conceptual building blocks (entities, spaces, times, properties, actions) from which propositional units are formed.

- Structuring

These components have to be structured with respect to possible frames of reference (e.g., spatial and temporal anchoring), predicate types and argument roles (agent, undergoer, for example), specification of informational status (topic-focus).

- Linearization

The units selected for verbalization have to be linearized in order to be presented both at a sentential and textual level in the one-dimensional medium of language production (cf. Levelt 1982; Klein and von Stutterheim 1989; von Stutterheim 1997).

At all the different stages in the planning process the speaker is confronted with a set of alternatives in deciding what to say and how to say it. In order to make a decision, the speaker has to adopt viewing points which may relate to the deictic origo, for example, as in the case of a factual spatial viewing point, or to abstract categories in information status such as topic-focus-assignment. That is to say that perspective taking at different levels and with respect to different conceptual domains is constitutive in planning the expression of 
complex information (cf. von Stutterheim and Klein 2002; Carroll and von Stutterheim 2003). One line in pursuing our central question on language specificity in text production is to look for the interrelation between languagespecific macrostructural patterns and grammatical means for perspective taking.

One of the core factors in the creation of a narrative text, for example, relates to the means by which events are linearized, i.e., represented as occurring in sequence. The principles used in sequencing events have been compared across languages which differ systematically with respect to their grammatical features, and with this the way in which the relevant conceptual domains (time, entities, space, action) may be structured when organizing information for expression (cf. Carroll and von Stutterheim 2003; Carroll and Lambert 2003; Carroll et al. 2008): The findings, which will be summarized briefly in the next section, form the basis for the present study on expository texts and the hypotheses on which the comparison was conducted.

\section{Language-specific patterns in information organization in narratives}

Our crosslinguistic studies on language specificity in information organization began with work on oral narratives, which is surely the most extensively analyzed text type in text linguistics. The data base consisted of oral film renarrations which were collected under comparable conditions for speakers using a short silent film as stimulus. Subjects were shown the film (7 minutes) and were then asked to tell what happened. 20 subjects were recorded per language group, producing narratives with an average length of 80 utterances per subject. Despite the past tense form in the introductory question, narratives were retold almost exclusively in the present tense ( $94 \%$ of all speakers across all languages).

As mentioned above, the focus of analysis was placed on factors that guide the decisions made in information selection (deciding what to say), in determining thematic continuity, referential framing (i.e., how predicate-argument structures are anchored with respect to times, worlds, entities, and spaces). In order for a sequence of propositions to be coherent, referential properties have to be related in consistent terms from one utterance to the next. The languages studied include English, French, Italian, Dutch, German, and Standard Arabic. ${ }^{2}$ The empirical studies were designed to test the role of different verbmorphological systems, coupled with specific word order constraints, in information organization. The findings which relate to language specificity in macro structural organisation can be summarized as follows:

- language-specific preferences in information selection (the types of entities referred to, level of granularity in event description, and references to endpoints/resultant states of events) 
- language-specific preferences in the temporal relations used to sequence events (temporal perspective)

- language-specific preferences in topic assignment and reference management.

To illustrate these general claims we will specify some of the results for English and German, focusing on the domain of time (temporal reference) as a core category for organising information in narrative text types (cf. Smith 2003: 25).

\section{Temporality}

The analyses of the film-renarrations with respect to temporal perspectivetaking show significant crosslinguistic differences which can be related to different patterns of macroplanning.

German speakers typically view events holistically as in the following examples: ${ }^{3}$

$\begin{array}{ll}\text {. . dann geht er zu der feuchten Stelle } & \text { bounded } \\ \text { 'then he walks up to the wet spot' } & \\ \text { und dann nimmt er einen Felsbrocken } & \text { bounded } \\ \text { 'and then he takes a piece of rock' } & \\ \text { und dann hämmert er ein Loch in den Boden } & \text { bounded } \\ \text { 'and then he hammers a hole in the ground' } & \end{array}$

The events are presented as reaching a point of completion, with no decomposition into sub-phases. In other words "bounded events advance narrative time" (Smith 2003: 27). The event times are hooked up intrinsically, an external temporal viewing point is not introduced for linking the event times across utterances.

In English frames of reference, by contrast, the event times are related to a temporal anchor given by an external narrator (now you see; then you see). This can be described as what is in the camera's range, so to speak. Events which are linked to this anchor, or to other events anchored in this way, can be segmented or decomposed into different phases, and the temporal perspective point is incorporated into the event time as the examples below illustrate:

(2) he is chiseling faster and faster unbounded as pieces of debris and metal and are getting pushed unbounded towards him and eventually he realizes bounded that he doesn't have enough time he gets crushed by the walls of the trash compactor bounded type thing 
and suddenly we see the sand

filtering through the rusted hole and the chiseled parts

unbounded of the earth

unbounded

Given these different temporal frames, English and German speakers evidence different patterns in representing events with respect to the feature "completed or not." 4 At some point in the planning process German speakers conceptualize events holistically and verbalize them accordingly. Temporal linkage is based on anaphoric relations whereby the point of completion of the preceding event is taken as the reference point for temporal shift. English speakers are more likely to present events as unbounded, compared to German speakers, and decomposition into different phases of the overall event (inceptive, middle, terminative) is more frequent. Temporal coherence is not established by a shiftin-time relation over the right boundary of the event time-interval. An extrinsic viewing point, which is maintained throughout the overall discourse, serves the function of defining a temporal reference frame at the level of macroplanning (cf. in detail Carroll et al. 2008). The possible basis for these different strategies can be found in contrasts in the two grammatical systems which are critical for the expression of temporal concepts: In contrast to German, the aspectual distinction 'event is ongoing' is grammaticalized in English via the progressive form. In Standard German ongoingness is expressed selectively by lexical means only. The crucial difference thus lies in the degree of grammaticalization of specific means for expressing aspectual viewpoints.

In order to test the factor 'grammaticalized concepts' against a possible factor 'cultural conventions', the languages studied were selected so as to control for the variable 'culture'. Standard Arabic can be taken as critical in this respect, since it clusters with English in the structural feature aspect, while English and German are closer in cultural terms. The findings were clear-cut: Patterns of event construal and temporal perspective taking in the Arabic-texts are similar to English. We thus hypothesized that differences in the grammatical system which relate to temporal categories form the locus for differences in information organization in narratives, rather than cultural conventions.

The analyses outlined above provide evidence of language-specific patterns in information organization that are typologically driven and hold not only at utterance level but also for the texts as a whole. So far these claims are based on analyses of narrative texts. In order to validate the hypothesis further, analyses have been extended to expository texts, since they differ fundamentally from narrative texts in information organization. Before moving on to the present analysis of expository texts, it is important to clarify the status of temporality in this context. In the literature, text modes which encompass arguments and information are described as atemporal (cf. Smith 2003). Atemporality usually refers to the fact that no specific temporal interval is assigned to the 
predication given by an utterance, i.e., there is no temporal anchoring on the time axis. Aspectual categories which are temporal in a relational but not referential sense are not taken into consideration in this context. Thus atemporality is a misleading term when it comes to the role of temporal concepts in discourse in general. In the study presented below, which is exploratory in nature, we set out to test the hypothesis that there are language-specific patterns of information organization in expository texts which can be traced to crosslinguistic differences in grammaticalized temporal categories.

\section{Expository texts}

In contrast to narratives, this text type cannot lay claim to having a welldescribed canonical structure that can function as a frame of reference for crosslinguistic comparisons. One of the problems encountered in the literature concerns the fuzzy boundary between argumentative and expository texts. In the following analysis expository texts will be defined rather broadly as texts which elaborate on and substantiate a personal opinion on the basis of empirical facts, thereby showing features of argumentation. The texts encompass different types of subtexts, each with its own place in serving a specific function within the overall text

Research on expository or argumentative texts has been carried out within very different disciplines. The traditional field of enquiry dates back to classical times, where emphasis was placed on the analysis of two logical components, the premise and the conclusion, taking into account the nature of these components and the way they are linked (Toulmin 1958).

In standard logical theory, one would define an argument as a passage of a set of statements, in which some statements, the premises, are put forward to support other statements, the conclusions. (Freeman 1991: 8)

Results in this field are typically presented in the language of logic, in order to avoid language-specific constraints on the formulation of general rules and principles of an abstract nature. The transformation of an argument into an adequate text structure is not under focus in these analyses, and questions as to how speakers or writers outline an argument in detail, what they decide to say first, what to mention explicitly or leave to be inferred etc., are not pursued in this context.

The construction of a line of argumentation has been a prominent topic in the field of education and a number of studies on expository texts have been carried out with this objective, in particular in relation to comprehension (Weaver and Kintsch 1991; Moss 2004). Emphasis has thus been placed on prescriptive aspects, i.e., features that make an expository text clear, compre- 
hensible, and convincing. The perspective is prescriptive and theoretical generalizations have not been sought for strategies actually applied, but for what speakers should apply, in contrast to the goal of the study at hand. Focus is not placed on diverging patterns in information organization and the factors that determine them, but rather on the search for an 'optimal', language-independent pattern. There are thus very few empirical studies of expository texts from a comparative perspective (Klein and Miller 1981), as a review of work in this field (Britton 1994) shows. We can therefore only agree with the claim that an "expository text constitutes a challenge for research" (Berman and Katzenberger 2004: 60), a claim which still holds.

\subsection{Some remarks on the structure of expository texts}

To begin with one of their basic characteristics, expository texts, in contrast to narrative or descriptive texts, do not follow an overarching structure in information organization (cf. Weaver and Kintsch 1991: 239f). However, they do provide an answer to an overarching twofold question: what is the case and why. The components of the text may differ in terms of informational status and function (specific facts, generic statements, evaluations), as well as the logical relations leading to a final conclusion: deductive, inductive, abductive or probative (Freemann 1991: 33). In this sense, the production of an expository text poses a particular challenge for the writer or speaker. The combination of units with different inherent constraints is facilitated through the presence of a main topic, enabling the speaker/hearer to establish a hierarchy between them. As models of arguments and their progression show, a unit of information can function as premise, as support for the argument, as an elaboration, or conclusion, depending on its position in the overall structure (Freemann 1991; Britton 1994). The specific function of a unit in a given text can be made explicit by connectors, for instance, or left to inference, a typical feature of expository texts: "The reader of an expository text has an additional obstacle, in that the structure building injunctions of an expository text are most often indirect, rather than direct" (Britton 1994: 652). One may therefore ask if the selection and serialization of information, as well as the supposed inferences, are guided by principles of a general nature. It is relevant to see whether what is made explicit and what is left to inference differs on a systematic basis or not. As Britton notes, inferencing can be a highly automatized and often unconscious - process in understanding a text.

The illusion [content structure building is signalled through linguistic means, cvs] is partly due to the fact that readers have developed procedural habits for dealing with implicit linguistic structure building instructions; these habits are automatised so that they do not normally appear in introspection. (Britton 1994: 652) 
We conclude this brief characterization of expository texts by highlighting possible features for analysis in crosslinguistic comparisons. Expository texts can focus on a general topic that integrates a number of potentially different informational components (facts, opinions, definitions, statements). Relations between these components can also differ (elaboration, specification, support, conclusion) and may often remain implicit. It is therefore a central objective of the analysis to see if there are macrostructural organization principles that follow a general pattern across languages, if there are options which are distributed across languages in an unsystematic way, or if we can identify languagespecific principles in guiding the speaker in the selection and organization of information for verbalization. The widely held view that "expository texts have a non-temporal, logical argumentative structure" (Ragnarsdottir et al. 2002: 96) will be reassessed on the basis of this explorative analysis.

The question underlying the study of expository texts follows from our findings on narrative texts. Given the fact that temporal features of situations are widely used as criteria in transforming non-linear material represented in memory into linearly ordered utterances/sentences, as well as in forming coherence at local and global levels in text production, we investigate whether linguistic systems which exhibit particular conceptual profiles in the domain of temporality also supply a scaffold for the speaker in forming complex conceptual structures that are relevant for the task. This is the case in narrative texts which show crosslinguistic differences in information organization. Although expository texts are viewed as being atemporal, the question is are there language specific patterns in the construction of expository discourse at all, and if so, is there any evidence that temporal categories play a critical role? To this end languages were selected on the basis of differences and parallels in their aspectual systems.

In studying the impact of structural features of a language on processes of conceptualization the inclusion of second language learners can serve as an additional window on this interrelation. Advanced learners, who no longer struggle with forms and words, can shed light on underlying strategies of information organization, since they have problems in restructuring the abstract and complex principles of information organization at a macrostructural level in text production, as previous studies have revealed (cf. von Stutterheim and Carroll 2006; Pavlenko 2011). On the basis of these findings second-language speakers were included in the study.

\subsection{The empirical study}

The data used for the following analyses are taken from a crosslinguistic project in which native speakers as well as L2 learners were asked to produce both 
a written narrative as well as an essay on the topic of "The impact of civilization on nature." ${ }^{5}$ The languages selected for the current study are German, Russian, Modern Standard Arabic, ${ }^{6}$ and the learner languages are L2-German (Russian as L1), L2-German (Arabic as L1). The three languages, German, Standard Arabic and Russian were again selected on the basis of contrasts in the temporal domain. Arabic and Russian have grammaticalized verbal aspect in that aspectual distinctions are marked on the verb, while aspect is represented by lexical means in German, and is only rarely used (see details below 5.3).

The participants are from comparably advantaged socio-cultural backgrounds, aged between 20 and 30. The L2 speakers acquired German as a second language as young adults, studying German at a German University up to a very advanced level (C2). ${ }^{7}$ The data were elicited at the University of Heidelberg under the same conditions for all groups and instructions were given in the writer's native language by a native speaker who assisted with the experiment. The L1 group of speakers and the L2s formed different groups, thus ensuring that there was no overlap. In order to give a common point of orientation, the participants were shown a short silent film about a creature (a clay man) who faces a series of obstacles in his quest for water in a threatening and disintegrating world. After seeing the film they were asked to write the essay, with no time limit. The only constraint was that the essay should be no longer than one page. The instruction given runs as follows, as exemplified by the English text:

"The film you just watched indicates many issues related to the impact of civilization on nature: lack of water, pollution, global warming, etc. What is your opinion on these issues and how could they be addressed? Would you please write a short essay, in which you present and discuss your views? The essay should not be longer than one page."

Each language group consisted of 24 subjects giving a total of 120 expository texts.

Table 1. Data overview: languages, number of subjects, total number of utterances ${ }^{8}$

\begin{tabular}{llll}
\hline L1 & German (G1) & Arabic (A1) & Russian (R1) \\
& $24 / 455$ & $24 / 595$ & $24 / 571$ \\
L2 & & German (A1G2) & German (R1G2) \\
& & $24 / 408$ & $24 / 497$ \\
\hline
\end{tabular}

The written data were transcribed in CHAT format (MacWhinney 2000). The texts were segmented at clause level. The data were coded at different levels of analyses and checked by two independent researchers (agreement 92\%). ${ }^{9}$ The analyses of macro-structural patterns were carried out on the basis 
of additional text functional categories, which are explained and illustrated below.

\subsection{Domains of analyses}

The instruction introduces a global topic: "the impact of civilization on nature" and asks for a personal evaluation of the problematic facts mentioned as well as a discussion of a possible solution to these problems. In terms of components at the macro structural level the requirements concern different types of information: a) facts related to the central topic, setting up the problem space b) personal evaluation of the problems c) conclusions with respect to solutions to the problems d) supporting argumentation for the solutions. Given these potential building blocks we focus on three general questions:

(i) How are these building blocks arranged at the macro-structural level?

(ii) Are there patterns which can be related to the respective language?

(iii) What role do temporal concepts play?

The texts of the different L1 groups were analyzed with respect to these questions and patterns were compared both crosslinguistically as well as with the learner texts; the L2 texts were also analyzed in their own terms, as well as in comparison to patterns found in the $\mathrm{L} 1$ texts.

The following aspects were taken as indicators for specific principles of organization:

(a) selection and sequential ordering of the different informational components, and (b) the overall frame of reference within which the content expressed unfolds, and with this the way in which the text opens. In accordance with earlier studies detailed comparative analyses were carried out on the order in which different types of information units are presented within the texts, with special focus on the introductory sections. As Berman and Katzenberger (2004) have argued:

Openings serve as the 'text organizer' in the discussion of a topic. The opening of an expository text serves to establish a pivot of generality along which the flow of information proceeds from general to specific and back to general. Thus, in expository discourse, generalizations are explicitly articulated in the opening and then elaborated by a specific commentary in the form of anecdotal or historical illustration, subcategorisations, and so on. (Berman and Katzenberger 2004: 59-60)

While we agree with the anchoring function of text openings, the analyses reveal that the content selected in fulfilling this function is not confined to information of one type. As will be shown below, temporal information, as expressed by morpho-syntactic and lexical means are taken as linguistic indicators of macro-structural organization. This introduces a third aspect in the 
empirical analysis: (c) the status accorded to temporal information and the expressive devices used.

\section{Results}

The findings for the crosslinguistic comparisons are presented for all five corpora, beginning with information organization, which is followed by analyses of the formal devices.

\subsection{Macro-structural patterns}

This level of analysis looks at how speakers linearize and combine different building blocks, focusing on the following types of core components.

Facts:

- specific facts my car is eco-friendly

CODE: fact

Generalized statements with two further subclasses:

- generic statements with no specification of reference time Der Mensch beutet die Natur aus 'mankind exploits nature'

CODE: gen.st. - ref

- general statements with specification of reference time everyday the media tell us about the danger of pollution.

CODE: gen.st.+ref.

Evaluative statements with two subcategories:

- personal attitude frame of the type I find that people do not care enough about nature

CODE: pers. att.

- conclusion based on personal opinion So wäre auf Dauer eine Veränderung zu bemerken

'this would result in a change in the long run'

CODE: pers. con.

On the basis of these categories the data exhibit two basic patterns that show differences in the way the line of argumentation is sequenced. The differences in linearization also reflect a difference in hierarchical organization.

\section{Pattern 1}

preferred by L1 German speakers

\section{Pattern 2}

preferred by L1 Arabic and Russian speakers 
1. pers. attitude

2. generic statements - ref

3. specific facts
1. specific facts or generalized statements + ref

2. personal evaluation

German speakers prefer a pattern (58\%) that starts with the expression of a personal standpoint (frame of reference is attitude based and temporally unspecific) to which general statements are linked; these can be backed by specific facts. Speakers of Arabic (70, 8\%) and Russian (79, 1\%) clearly prefer a different structure. Although both languages have a verbal form (imperfective) which can be used without reference to a temporal anchor to make general statements, Arabic and Russian speakers start by establishing a referential frame with temporally (and often spatially) anchored information. General statements are integrated within this frame. Personal statements may be added as a comment on the embedded general statements. However, with this latter pattern (2), the conclusion with respect to the general topic of the argument often remains implicit.

In overall terms the two patterns differ with respect to what is made explicit, with respect both to degree as well the domains where this occurs. In pattern 1, explicit information that guides the reader is anchored in a frame based on personal attitude (pers. att.) and evaluations, where causal connectors, or modal adverbials, indicate how informational units are anchored within the overall line of argument. The following segment from a German expository text illustrates this pattern:

(3) Für mich ist es keine Frage

'for me it is no question'

ob die Auswirkungen der Zivilisation

auf die Natur gravierend sind.

'if the consequences of civilization on nature are serious'

Zum großen Teil sind die Auswirkungen negativer Art.

'for the most part the consequences are of a negative nature'.

Ich denke,

'I think,'

dass es wichtig ist,

'that it is important,'

bei kleinen Problemen anzufangen, 'to start with minor problems,' pers. att

embedded statement

gen. st. - ref (as reinforcement)

pers. att.

embedded personal evaluation

embedded conclusion 
gerade wenn man etwas dagegen

unternehmen will.

'all the more if one wants to do anything embedded condition about them.'

Unter Umweltverschmutzung kann ich

mir viel vorstellen,

'I can imagine a lot when it comes to pers att.

pollution'

da es meinen Alltag betrifft.

'because it concerns my every day life.' embedded cause $(\mathrm{S} 03, \mathrm{G} 1)^{10}$

Arabic and Russian speakers show a clear preference for pattern 2. The texts start with referentially bounded facts or statements, with informational units presented as specific expansions of the topic introduced. ${ }^{11}$ The functions as well as the position of these facts within the line of argument serve in preparing the ground for the general conclusion; this crucial part of the argument may remain implicit, however.

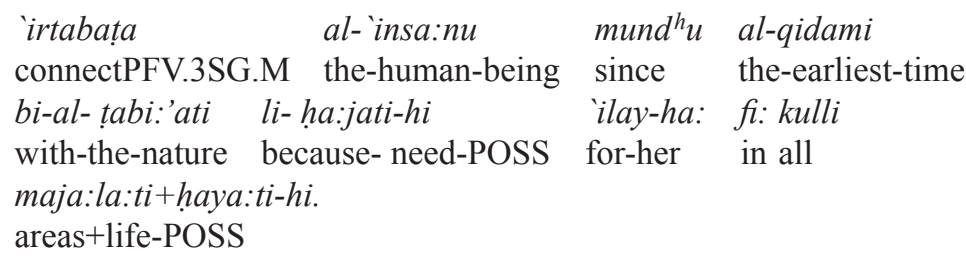

'Human beings are linked to nature since earliest times because of their dependence on it in all areas of life'

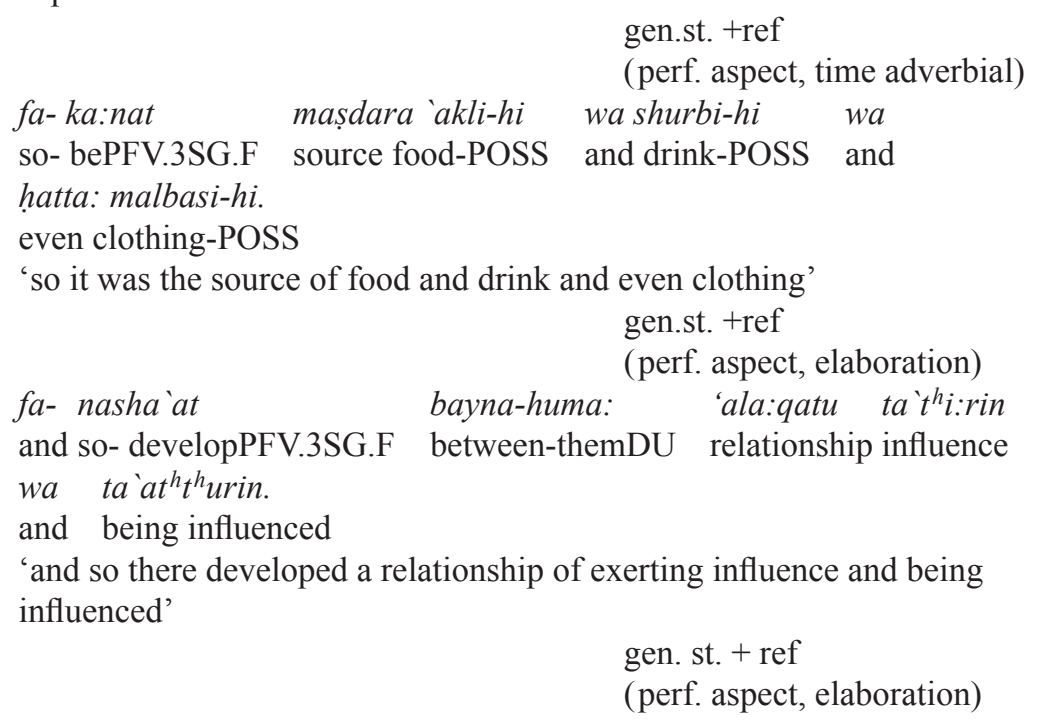


qa: imatan li-haddi al-`a:n.

existPTCP until point now

'which exists up to today'

gen. st. + ref (time adverbial, elaboration)

la:kin ma'a al-tatawwuri [\& allad ${ }^{h}$ : wașala 'ilay-hi al- insa:nu but with the-progress [\& REL arrivePFV.3SG.M to-him thetaknu:lu:jiyyan] 'aṣbaha bi- țari:qatin

human-being technologically] becomePFV.3SG.M with-way

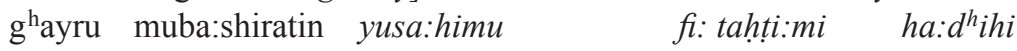
NEG directly involveIPFV.3SG.M in destruction DEM al-bi: 'ati al-jami:lati

the-nature the-wonderful

'but with the progress which humans have achieved in technology man began in an indirect way to be involved in the destruction of this wonderful nature' gen. st. +ref. (perf. aspect) (consequence)

allati: ra:faqat-hu fi:kulli mara:hili +haya:ti-hi. REL accompanyPFV.3SG.F-him in all stages +life-POSS 'which accompanied him in all stages of life'

gen. st. +ref.(perf. aspect) (specification)

wasa:hamat fi: 'istimra:ri-hi li-haddi al- 'a:n. an involvePFV.3SG.F in continuation-POSS until-point now 'and still does so in his survival up to today' gen. st. +ref.(perf. aspect, time adverbial)

$(\mathrm{S} 16, \mathrm{~A} 1)$

The Russian text (Example 5) exhibits a comparable structure.

(5) Global'nye ekologičeskie problemy pojavilis' global ecological problems appear: PF.PRT.PL. ne segodnja.

not today 'global ecological problems didn't appear today'

gen.st. +ref

(perf. aspect, time adverbial)

no dalee ešče otnositel'no nedavno v seredine dvadcatogo veka but further until quite recently in half twenty century nikto ne zadumyvalsja ne tol'ko o nobody not give thought: IMPF.PRT.3.SG. not only about putjach rešenija ways of solution 
'but until some time ago at the mid-20th century nobody worried about decision making'

no daže o suščestvovanii takich problem.

but also about existence of such problems

'but also about the existence of such problems'

gen.st. + ref

(past tense, time adverbial)

Gosudarstva lišs' pytalis'izvleč'

(elaboration)

states only try: IMPF.PRT.PL. to extract: PF.INF.

vse vozmožnye prirodnye resursy.

all possible natural resources

'the states only tried to extract all possible natural resources'

gen.st. +ref

(past tense,perf. aspect)

ne zadumyvajas'.

not give thought: IMPF.ADV.PART.

'not worried about'

kakie posledstvija takaja bezpoščadnaja dejatel'nost'

which consequences such merciless activity

prineset v skorom buduščem.

bear: PF.FUT.3.SG in near future

'which consequences such a merciless activity will bear in the near future'

$(\mathrm{S} 12, \mathrm{R} 1)$

gen.st. + ref

(future, perf. aspect, time adverbial)

The comparison of the patterns 1 and 2 underlines the claim made by Britton as cited above whereby different structures go hand in hand with different inferencing strategies on the side of the reader.

\subsection{Openings}

Openings establish the frame for the text as a whole, and opening segments typically start with the introduction of central referential categories (Berman and Katzenberger 2004: 64-65). ${ }^{12}$ These informational components constitute the main structure of the text in that the process of information selection is scaffolded by these "fixtures". The analysis of referential features of the opening utterances for German, Arabic, Russian, and the two learner languages, are shown in Table 2. This gives the number of subjects per language that start the expository text with the respective type of anchor. 
Table 2. Type of referential frame referred to by subjects per language group ${ }^{13}$

\begin{tabular}{|c|c|c|c|c|c|}
\hline & German L1 & Arabic L1 & Russian L1 & German L2 (A1) & German L2 (R1) \\
\hline $\begin{array}{l}\text { reference to } \\
\text { speaker in } \\
\text { pers. att. }\end{array}$ & 14 & 0 & 0 & 2 & 2 \\
\hline gen. st. + ref. & 5 & 17 & 19 & 16 & 12 \\
\hline gen. st. - ref & 5 & 7 & 5 & 6 & 9 \\
\hline
\end{tabular}

In order to illustrate these different strategies examples will be given from both the L1 and L2 texts.

(6) Ich erachte es für wichtig

pers. att.

'I find it important'

dass sich jeder Mensch mit der Auswirkung der Zivilisation auf die

Natur auseinandersetzt

'that every man considers the influence of civilization on nature'

da dies Themen sind

gen. st. - ref. (embedded)

'because these are topics'

die jeden Mensch betreffen ...

gen. st. - ref. (embedded)

'that concern every individual'

gen.st. (embedded)

(S01, G1)

(7) 'inna al-wa:qi'a [alladhi: na'i:shu-hu alyawma]

certainly the-situation [REL experienceIPFV.1PL-him today]

jiddu mutațawwirun

very serious

'certainly the situation [which we today experience] is very serious'

gen. st. +ref.

la:kin ragh ma kulli al-taqaddumi [allad ${ }^{h}$ : haqqaqa-hu

but despite whole the-progress [REL reachPFV.3SG.M-him

al- insa:nu] xa:șșatan fi:maja:li+al-taknu:lu:jiya:

the-human being] particular in area+the- technology

'but despite whole progress [which mankind has reached] in particular in the area of technology'

allati: raqat

$$
\text { bi- al- 'insa:ni ila: 'a'la: }
$$

REL rise-upPFV.3SG.M which the- human being to higher al-daraja:ti.

the- level

'which mankind to the highest level has brought'

gen.st. +ref. (embedded) 


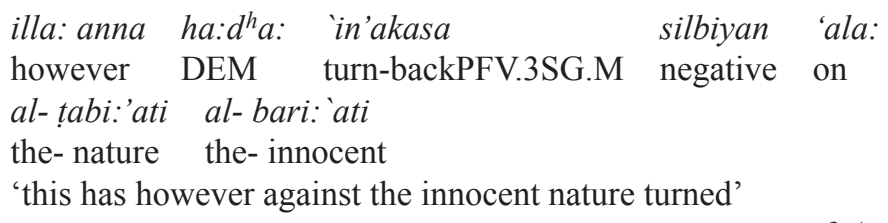

gen.st. +ref. (embedded)

(S03, A1)

A comparison of the two openings exemplifies the role and implications for information organization within the different frames. In the German text, an attitude-based frame provides the grounds for the status of the general claim made. The speaker, by means of self reference, leads the reader through the causal chain, and subordinated constructions reflect the hierarchical organization. Arabic speakers start out with reference to a temporally anchored situation. This is elaborated on by statements that are again temporally located (by aspectual markings). Temporal reference functions as the central domain for coherence and general statements are marked as dependent by means of downgrading (subordination). The relationship between the information given in the clauses involves specification and elaboration. The same type of information organization is preferred by speakers of Russian, as illustrated in the following example:

(8) čelovek samyj

strašnyj parazit na tele zemli

man the (most) bad parasite on body of earth

' $m a n$ is the worst parasite on the face of the earth'

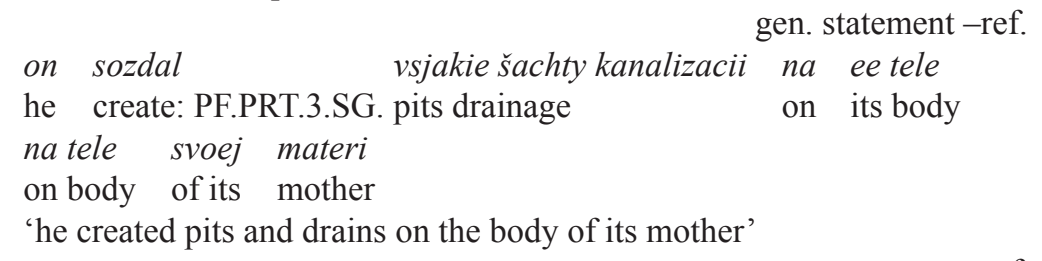

i teper' on vykačivaet

gen. statement + ref.

and now he pump-out: IMPF.PRS. 3.SG. from it everything

'and now he pumps out everything from it'

\begin{tabular}{lllll} 
vozmožno $\quad v$ buduščem & \multicolumn{2}{c}{$v$ sja } & \multicolumn{2}{c}{ planeta budet } \\
perhaps $\quad$ in future & all planet will \\
sostojat & & $i z$ & sacht $i$ & skvažin \\
consist:IMPF.FUT.3.SG & of pits and & wells
\end{tabular}

'perhaps all planets will consist of pits and drains in the future'

$(\mathrm{S} 08, \mathrm{R} 1)$

gen. statement + ref. 
The Russian speaker starts with an introduction similar to the one presented above in the native Arabic text. The general claim is anchored on a temporal basis and elaboration occurs by adding more specific information, thereby maintaining the referential frame established in the first sentence. This presentation of information of increasing specificity is not explicitly embedded in an argumentative frame at a higher level. It differs in this respect on a fundamental level from the native German texts and is similar to the L1 Arabic texts. ${ }^{14}$

The analysis of the L2 data reveals clear preferences with regard to the selection of a referential frame, as indicated in table 3 above. The Arabic and Russian learners of German start with references to temporally anchored situations. These are followed up by statements that are also temporally located by aspectual markings, showing that temporal reference functions as the central domain in creating coherence. The following example is taken from the L2 corpus.

(9) Eine(s) der vielen Probleme der heutigen Zeit ist die

Umweltverschmutzung

'one of the many problems of the present day is environmental pollution' gen.st. + ref.

der moderne Mensch kann nicht mehr ohne Autos auskommen 'modern man cannot do without cars anymore' gen.st. + ref.

das wiederum in einer der zahlreichen Fabriken hergestellt wird 'that is again manufactured in one of the many factories'

fact + ref. (embedded)

(S04, G2 A1)

The type of opening found in 9 does not occur in the L1 German texts. The L2 text is marked by the absence of causal linkage between a general statement and a rather specific fact. Translated into Arabic, however, it is an acceptable text for native speakers of Arabic.

The opening section of an expository text establishes the global frame for the whole text. In contrast to assumptions in the literature for this text type, there is no evidence of there being one general framing principle which applies across all the language groups studied. Arabic and Russian speakers prefer a pattern of organization where temporal anchoring constitutes the principal means used in creating coherence at the macro-structural level. A comparison of the texts with respect to the overall occurrence and function of specific temporal references confirms the findings. The percentages given in Table 3 are based on the number of speakers who refer to specific temporal intervals. All speakers of Arabic and Russian refer to specific temporal intervals at different points throughout the text, in contrast to German speakers where only one quarter of the speakers introduces information that is anchored specifically in 
Table 3. Temporal reference by speakers in texts $(n=24)$

\begin{tabular}{llllll}
\hline & German L1 & Arabic L1 & Russian L1 & German L2 (A1) & German L2 (R1) \\
\hline $\begin{array}{l}\text { Speakers that } \\
\text { refer to specific } \\
\text { temp. intervals }\end{array}$ & $25 \%$ & $100 \%$ & $100 \%$ & $75 \%$ & $82 \%$ \\
\hline
\end{tabular}

time (taking all temporal anchors at all levels in the text). The remaining $75 \%$ of the German speakers use no temporal adverbials, only the present tense, which, however, does not identify any specific temporal interval. On these grounds temporal features of the information given do not provide a criterion for establishing coherence.

The pattern found for the learners clusters with those of their mother tongue group.

Let us briefly summarize the crosslinguistic findings at the level of macrostructural organization for the expository texts. Speakers of all languages draw upon the same set of components or building blocks in anchoring information in context, but not in the same way, as reflected in the hierarchical and text functional status. The crosslinguistic analysis suggests that these differences cannot be explained as a matter of personal style since they co-vary with the languages used. The two patterns described above differ with respect to the status accorded to the temporal domain in the organization of information for expression and the associated differences for the level of specificity with which situations are anchored.

Coming now to the possible basis for these preferences, the fact that Arabic speakers cluster with Russian speakers means that cultural factors are unlikely as an explanation with respect to the use of temporal anchoring. Given the results from the study on narratives, where grammaticalization of temporal categories proved to be a critical factor in determining information organization, the present findings allow us to set up the hypothesis that it is again temporal categories which play an eminent role in information organization. In contrast to German, Arabic and Russian have a fully grammaticalized aspectual system, as mentioned above. The use of linguistic means expressing temporal categories, and the diversity thereof across languages will be taken up in detail in the next section.

\subsection{Temporal reference and verbal categories}

All three languages in the study, German, Arabic, and Russian, are languages in which temporal categories are marked morphologically on the verb. In 
German, the system offers options with respect to temporal reference, mainly in the form of tense, ${ }^{15}$ while Arabic speakers have to select temporal anchors across the aspectual perfective-imperfective opposition, complemented by periphrastic forms that include further aspectual and time referential categories, in addition to modal distinctions. Russian has the richest system in morphological terms in that the finite verb is marked for tense as well as aspect.

Table 4. Overview of grammaticalized temporal categories

\begin{tabular}{llll}
\hline $\begin{array}{l}\text { Temporal categories } \\
\text { grammaticalized }\end{array}$ & Arabic (MSA) & Russian & German \\
\hline Tense & no & yes & yes \\
Imperfective & yes & yes & no \\
Progressive & yes & no & no \\
Perfective & yes & yes & no \\
\hline
\end{tabular}

The verbal forms used in the expository texts by German speakers cover basically one form - the present tense. This tense in German is 'bleached' with respect to its temporal features. In some analyses the present tense is considered to be an atemporal form (cf. Zifonun et al. 1997). The present tense is thus an optimal way of making generic references, since statements in the present tense do not require further temporal anchoring; this tense "does not need capture", as stated in Smith (1991).

Table 5. Distribution of tense forms in German L1 and L2 ( $n=24$ per group)

\begin{tabular}{lccc}
\hline & German L1 & German L2 (A1) & German L2 (R1) \\
\hline present tense & $94 \%$ & $87 \%$ & $84 \%$ \\
present perfect & $3 \%$ & $8 \%$ & $6 \%$ \\
simple past & $2 \%$ & $4 \%$ & $5 \%$ \\
Future & $1 \%$ & $1 \%$ & $4 \%$ \\
\hline
\end{tabular}

Arabic and Russian speakers, by contrast, use a range of different aspectual forms; the imperfective being the most frequent, followed by the perfective. Tables 5, 6, and 7 present an overview of the forms for each language.

A breakdown of the verbal forms used in the texts shows that German speakers mainly use one verb form, the present tense, with no further temporal specification of the situation referred to. Russian and Arabic speakers, in contrast, use a range of verb forms, forms which have or imply a temporal perspective. To pinpoint the difference: for Russian and Arabic, no statement is made 
Table 6. Distribution of verbal forms for Arabic $(n=24)$

\begin{tabular}{lr}
\hline zero (0-copula, no time ref.) & $16.6 \%$ \\
\hline imperfective & $40.4 \%$ \\
perfective & $20.3 \%$ \\
future time (sa, sawfa) & $2.0 \%$ \\
past time (kana) & $1.2 \%$ \\
modal constructions & $8.6 \%$ \\
participial constructions & $1.3 \%$ \\
rest & $9.6 \%$ \\
\hline
\end{tabular}

Table 7. Distribution of verbal forms for Russian $(n=24)$

\begin{tabular}{lc}
\hline zero (0-copula, no time ref.) & $14.0 \%$ \\
\hline imperfective present & $29.2 \%$ \\
imperfective future & $4.8 \%$ \\
imperfective preterite & $3 \%$ \\
imperfective participle & $4 \%$ \\
perfective participle & $2 \%$ \\
perfective future & $8 \%$ \\
perfective preterite & $7 \%$ \\
Infinitive & $4 \%$ \\
modal constructions & $16 \%$ \\
Rest & $8 \%$ \\
\hline
\end{tabular}

without some kind of specification of the topic time interval, i.e., the time span for which the assertion holds, since aspect requires temporal anchoring (cf. Klein 1994). In German, the use of the present tense does not attract temporal specification, unless used in opposition with other tenses. This is not the case with generic or habitual statements. Arabic and Russian learners of German have to contend with what the comparatively poor temporal system of German has to offer. They make more use of tense shift, and there is a tendency to specify temporal reference by means of adverbials. The following example from the text of a Russian learner of German illustrates this pattern.

(10) ... die Probleme sind heutzutage (time adv.) viel extremer, 'the problems are today much more extreme'

da durch die technische Entwicklung man zwar Vorteile für sich geschaffen hat (present perf.), 'because by technical development one advantages for oneself has created' 
aber die Nachteile, die die Natur dadurch erlitten hat (present perf.), spürt auch der Mensch

'but the disadvantages, which nature thereby has suffered, notices also man'

(S11, G2 R1)

Temporal anchoring is a core feature in conceptual planning at the macrostructural level in the L2 data, a factor which may not always be captured in quantative terms: "In a closed system, choice of one term implies contrast with the other possibilities. The element of choice and its contrastive significance allows for more than one level of discourse meaning." (Smith 2003: 1)

The diverging patterns reflect the differences in the macroplanning principles used. The tendency in Arabic and Russian texts to establish a frame of reference which establishes a temporally specified world is mirrored in the selection of factual, referentially bounded information at the topmost level in information organization. The selection of a temporal perspective has a grammatical basis in the languages and may be the trigger for the observed strategies in information organization found for these texts. German has neither a comparable grammatical system nor associated constraints in the domain of temporality. Therefore, the factors that have to be considered in drawing up an argumentative structure can proceed with a default situation in the temporal domain (present tense) without assigning any role to temporal reference and specific relations, thus giving rise to a strategy which establishes causal relations as the main factor in creating coherence.

\section{Summary of findings}

"Expository introductions typically take the form of generalizations that form the basis for increasingly specific information as the text proceeds. The flow of information provided in an expository piece of discourse typically proceeds from general to specific, a progression which constitutes the organizing pivot of the text as a whole." (Berman and Katzenberger 2004: 76-77)

In contrast to previous assumptions for expository texts, the analysis of texts by German, Arabic and Russian writers reveals different crosslinguistic principles in organizing information for expression. The present study investigated the extent to which decisions made at this level are guided by factors that are grammatically determined and operate at a macro-level of organization for the text. Grammatically determined patterns were evidenced in

- language-specific principles that determine the line of argument in hierarchical terms, in particular the referential frame selected at the topmost level of the macrostructure; 
- language-specific functions accorded to the domain of temporality, in particular the status of referentially anchored information.

The analyses of the texts of advanced adult second language learners support the findings in that they also provide evidence of language-specific (L1) principles in key functions. With respect to the relevant grammatical features, Arabic and Russian texts form one group in that guidelines for information organization proceed on the basis of specific temporal properties by which arguments and the units they form are related temporally. This principle is not found in L1 German texts. German speakers follow a frame of reference based on personal attitude in which argument units are anchored in temporally neutral terms (unspecific temporal reference) and related on a causal basis.

It is important to note that this relates to components of the argument that are explicitly mentioned. Given the crucial role of temporal information in the contrasts observed, and the correlation with grammaticalized distinctions, the findings provide support for the relevance of grammatical means as a driving force in information organization. Arabic and Russian, the two languages in the study with fully grammaticalized verbal aspect, form a cluster for one of the patterns observed, while German speakers follow guidelines in information organization in which contrasts in temporal reference do not play a central role.

\section{Discussion}

The crosslinguistic studies of two different text types show how speakers or writers follow organizing principles at the level of macroplanning in text production which can be linked to grammaticalized means. The principles at issue guide the speaker in selecting information from a knowledge base, in establishing a global frame of reference (perspective taking), and in determining patterns of information structure for the text as a whole. Planning principles of this kind enable the speaker to create a coherent text on the scale required, and provide the basis for the integration of information within a hierarchical structure.

The findings for the two text types expository and narration point to the role of the temporal domain in determining the frames of reference that hold at a global level in information structure. Crosslinguistic differences in sequencing events in narratives are given with the type of temporal frame selected - an external deictic anchor in the case of English and Modern Standard Arabic, and an intrinsic temporal anchor in German, based on events that are presented as bounded. In the latter case the narrative sequence is established within the temporal chain by linking the current event and its time of situation (the topic time or time of assertion) to the preceding time of situation and its point of 
completion (cf. in detail Klein 1994). This means that the reference point required in advancing the temporal chain of events is provided by the preceding time of situation as a bounded event. The different crosslinguistic preferences can be linked to the grammatical means which these languages provide in encoding temporal-aspectual relations.

In the expository texts the crucial crosslinguistic difference observed in information organization is again temporal and relates to the implementation on a global basis of specific versus unspecific temporal references in anchoring units of the argument presented. This choice has implications both for the type of information selected as well as the means available to the writer in creating coherence. In the German expository texts temporal reference does not function as the organizing force in creating coherence, since it remains unspecified. This means that other domains take on this function. Arabic and Russian writers, on the other hand, establish a temporal reference frame and associated guidelines which provide a criterion in selecting as well as linking information. The crosslinguistic clusters found in the analyses (e.g., Arabic and Russian) correlate with similarities in the temporal-aspectual systems, rather than cultural traditions in rhetorical style. In the process of planning and organizing content for expression, the linguistic knowledge and conceptual structure that allow speakers to execute the task make use of the formal means available, and meet the constraints in the creation of coherence given with the linguistic system used. In keeping with the view in cognitive linguistics (Bybee 1985; Talmy 1985, 1996; and going back to Jakobson 1971 [1959]), we assume that grammatical categories of this kind play a fundamental role when organizing information for expression: temporal inflectional categories are not only obligatory but highly abstract (i.e., applicable to word class paradigms, independent of the items' specific meaning) and are fully automatized in use. They provide a conceptual grid or frame for mental processing and decision making - at least whenever language is involved. ${ }^{16}$

Theoretical considerations along these lines are rarely extended to the concept of macroplanning in text production and the means adopted in creating coherence on the scale required. In bringing together what has been said concerning the central function of inflectional categories for conceptualization and the present empirical results on cross-linguistic differences in patterns of macroplanning, we find support for our hypotheses. Grammatical categories impose constraints not only at sentence level but also on the way in which information is referentially framed and linked across the domains of time, space, entities, different worlds, as found in text structure.

The implications of grammatical categories for conceptualization and information structure are acquired on what proves to be a long road to native proficiency in L1 acquisition, since acquisition continues until the age of 13 or 14 before speakers master the relevant principles underlying macroplanning with 
all their ramifications (Berman and Katzenberger 2004; Halm 2010). These fundamental processes are then highly automatized and need not be subjected to further stages of revision and reflection in the L1. This is the point at which studies on very advanced second language learners are highly relevant, since they provide a window on the nature of linguistic knowledge at this level. As shown in the present study, ${ }^{17}$ the L2 speakers - although fully competent in all formal respects - maintain principles of macro structural organization in conceptualizing and organizing content in their L2. As extensive crosslinguistic studies on narratives in L2 have shown, principles of perspective taking are particularly hard to reorganize or acquire anew. The task facing the learner becomes all the more demanding if there are no formal correlates in the input which focus the attention of the learner. This was shown for L2 learners from English to German and vice versa. It is harder for an English speaker to detect and acquire the boundedness constraint in German than for a German speaker to acquire principles of phasal decomposition (cf. von Stutterheim and Carroll 2006; Carroll and von Stutterheim 2003). These differences can be explained by the fact that there is a salient formal correlate - the progressive - in the English system, whereas there is no functional correlate to mark a holistic perspective on events in the German system. In the context of the expository texts the Arabic and Russian learners of German are confronted with the same problem. The main hurdle for advanced learners is to filter out the principles on which their L1 is based when using the L2. With respect to the domain of temporal perspective taking they move from a richer, more differentiated system to a system which is less differentiated. In this case learners will have difficulties in uncovering the implications of the grammatical means acquired with the L2 in creating coherence across different semantic-conceptual domains. The findings for the L2s can be taken as further evidence for language-specific patterns in information organization.

Received 29 April 2009

Revised version received 13 December 2010

University of Heidelberg

\section{Notes}

1. This study was funded by the German-Israeli-Foundation (GIF, The Impact of the L1 on Advanced Learner Languages: A cross-linguistic study of spoken and written usage) and the German Science Foundation (DFG). We would like to thank both institutions for their support. The GIF-project was carried out in collaboration with R. Berman, University of Tel Aviv. We would also like to thank two anonymous reviewers for helpful comments on the first version of the article. Correspondence address: Christiane von Stutterheim, Institut für Deutsch als Fremdsprachenphilologie, Plöck 55, 69117 Heidelberg, Germany. E-mail: stutterheim@idf.uni-heidelberg.de 
2. Other languages in the corpus are Norwegian, Spanish, Czech, Russian, Polish, Chinese, Japanese (Tomita 2008; Sahonenko 2004; Sledzka 2006).

3. Examples (1) and (2) were taken from the corpus of film-renarrations, collected at the Institute for German as a Foreign Language Philology at the University of Heidelberg.

4. This finding contrasts with the claim "Narrative time advances with bounded events, and explicit temporal adverbials. It fails to advance otherwise." (Smith 2003: 26) As the example of English shows, the claim is too narrow and does not take narrative strategies into account in which the interpretation of the dynamics of an event sequence can rely on inferences based on verb meaning and world knowledge, in addition to bounded events.

5. The GIF-Project (see Note 1). The languages studied include English, German, Russian, Hebrew, Arabic, and the learner languages are L2-German (Russian as L1), L2-German (Arabic as L1), L2-English (German as L1, Hebrew as L1).

6. Arabic speakers (both the L1 and L2 group) are from different Arabic-speaking countries. The subjects were asked to use Standard Arabic, which for all participants is the variety used when writing. The data were transcribed in CHAT format (MacWhinney 2000), and structural information was added where relevant.

7. According to the Common European Framework of Reference (CEFR, 2001) C2 corresponds to "mastery".

8. Utterance-units (propositions with a predicate-argument structure) form the units of analysis corresponding to the syntactic definition of a clause.

9. Coding encompasses categories for linguistic form and syntactic structure as well as functional analyses of textual units. For the present analysis, codes for the verb phrase and its temporal features were used: finite verbs, including auxiliaries and full verbs, tense, grammatical aspect.

10. ' $\mathrm{S}$ ' indicates the subject number within the subject groups. 'A1/G1/R1' indicates the groups of Arabic/German/Russian native speakers. The abbreviations 'G2 A1' means Arabic second language learners of German, 'G2 R1' means Russian second language learners of German.

11. We add codes for expressive devices giving temporal information.

12. Berman and Katzenberger (2004) analyze openings in narrative and expository discourse under a developmental perspective. They find that the central structuring function of the openings is a crucial feature of expository texts, and this function is not mastered before the age of 14 .

13. All codings were carried out by two independent researchers, agreement was at $92 \%$.

14. A study on comprehension of argumentative texts, comparing Spanish and Arabic learners of English, provides relevant results on this point. "La version explicitement causale facilite les rappels des hispanophones alors que chez les arabophones, la version des type descriptif a un effet facilitateur." (Carrell 1990: 21) The study on text comprehension seems to mirror the different patterns found in text production.

15. This is admittedly a rather unsubtle characterization, but see Klein (1994) on the theoretical background.

16. Crosslinguistic analyses of direction of attention reveal how speakers of different languages exhibit different patterns of visual attention when talking about events. Eye tracking experiments in which speakers were asked to view and then verbalize, information on events presented in short video clips show significant correlations between linguistic systems and focus of visual attention. The findings can be taken as evidence for an interaction between linguistic features, conceptualization and focus in perception (von Stutterheim and Carroll 2006).

17. For further aspects on advanced L2 production see Carroll (2008), Carroll and Lambert (2006), von Stutterheim and Carroll (2006). 


\section{References}

Antos, Gerd, Klaus Brinker, Wolfgang Heinemann \& Sven F. Sager (eds.). 2000. Text- und Gesprächslinguistik. (Ein internationales Handbuch zeitgenössischer Forschung. HSK 16.2.) Berlin \& New York: Mouton de Gruyter.

Berman, Ruth \& Dan Slobin. 1994. Relating events in narrative: A crosslinguistic developmental study. Mahwah, NJ: Lawrence Erlbaum.

Berman, Ruth \& Irit Katzenberger. 2004. Form and function in introducing narrative and expository texts: A developmental perspective. Discourse Processes 38 (1). 57-94.

Britton, Bruce K. 1994. Understanding expository text: Building mental structure to induce insights. In Morton Ann Gernsbacher (ed.), Handbook of psycholinguistics, 641-674. New York: Academic Press.

Bybee, Joan L. 1985. Morphology: A study of the relation between meaning and form. Amsterdam \& Philadelphia: John Benjamins.

Carrell, Patricia. 1990. Culture et contexte dans une langue étrangère: Rôle des schémas de contenu et des schémas formels. In Daniel Goanac'h (ed.), Acquisition et utilisation d'une langue étrangère: L'approche cognitive, Le Français dans le monde: Recherches et applications, 16-29. Paris: Hachette.

Carroll, Mary. 2008. Macrostructural planning and topic shift in narrative discourse: Advanced English learners of German. In Giuliano Bernini, Lorenzo Spreafico, Ada Valentini (eds.), Competenze testuali e discursive nell'acquisizione di lingue seconde, 34-50. Perugia: Guerra.

Carroll, Mary \& Monique Lambert. 2003. Information structure in narratives and the role of grammaticised knowledge: A study of adult French and German learners of English. In Christine Dimroth \& Marianne Starren (eds.), Information structure and the dynamics of language acquistion, 267-287. Amsterdam \& Philadelphia: John Benjamins.

Carroll, Mary \& Monique Lambert. 2006. Reorganizing principles of information structure in advanced L2s: A study of French and German learners of English. In Heidi Byrnes, Heather Weger-Guntharp \& Katherine Sprang (eds.), Educating for advanced foreign language capacities, 54-73. Georgetown: Georgetown University Press.

Carroll, Mary, Antje Rossdeutscher, Monique Lambert \& Christiane von Stutterheim. 2008. Subordination in narratives and macrostructural planning: A comparative point of view. In Cathrine Fabricius-Hansen \& Wiebke Ramm (ed.), Subordination versus coordination in sentence and text, 161-184. Amsterdam \& Philadelphia: John Benjamins.

Carroll, Mary \& Christiane von Stutterheim. 2003. Typology and information organization: Perspective taking and language-specific effects in the construal of events. In Anna Giacalone Ramat (ed.), Typology and second language acquisition, 365-402. Berlin \& New York: Mouton de Gruyter.

Council of Europe. 2001. The common European framework of reference for languages. 2001. Cambridge: Cambridge University Press. http://www.coe.int/t/dg4/linguistic/ (accessed 6 Jan 2012)

Evans, Nicholas \& Stephen C. Levinson. 2009. The myth of language universals: Language diversity and its importance for cognitive science. Behavioral and Brain Sciences 32(5). 429492.

Freeman, James B. 1991. Dialectics and the macrostructure of arguments: A theory of argument structure. Berlin \& New York: Foris.

Gumperz, John J. \& Stephen C. Levinson (eds.). 1996. Rethinking linguistic relativity. Cambridge: Cambridge University Press.

Gentner, Dedre \& Susan Goldin-Meadow (eds.). 2003. Language in mind: Advances in the study of language and thought. Cambridge/MA: MIT Press. 
Halm, Ute. 2010. Die Entwicklung narrativer Kompetenz bei Kindern im Alter zwischen 7 und 14 Jahren. Marburg: Tectum.

von Humboldt, Wilhelm. 1998 [1836]. Über die Verschiedenheit des menschlichen Sprachaufbaus und ihren Einfluß auf die geistige Entwicklung des Menschengeschlechts. Paderborn: Schöningh.

Jakobson, Roman O. 1971 [1959]. Boas'view of grammatical meaning. In Selected writings, vol. 2, 489-496. The Hague: Mouton.

Klein, Wolfgang. 1994. Time in language. London \& New York: Routledge.

Klein, Wolfgang, \& Max Miller. 1981. Moral argumentations among children. A case study. Linguistische Berichte 74/81. 1-19.

Klein, Wolfgang \& Christiane von Stutterheim. 1989. Referential movement in descriptive and narrative discourse. In Rainer Dietrich \& Carl Friedrich Graumann (eds.), Language processing in social context, 39-76. Amsterdam \& Philadelphia: Benjamins.

Lee, Penny. 1996. The Whorf theory complex. A critical reconstruction. Amsterdam \& Philadelphia: John Benjamins.

Levelt, Wilhelm J. M. 1982. Linearization in describing spatial networks. In Stanley Peters \& Esa Saarinen (eds.), Processes, beliefs, and questions. Essays on formal semantics of natural language and natural language processing, 199-220. Dordrecht: Reidel.

Levelt, Wilhelm J. M. 1989. Speaking: From intention to articulation. Cambridge, MA: MIT Press.

Levinson, Stephen. 2003. Language and mind: Let's get the issues straight! In Dedre Gentner \& Susan Goldin-Meadow (eds.), Language in mind: Advances in the study of language and cognition, 25-46. Cambridge, MA: The MIT Press.

Levinson, Stephen. 2006. Grammars of space. Cambridge: Cambridge University Press.

Li, Peggy \& Lila Gleitman. 2002. Turning the tables: Language and spatial reasoning. Cognition 83(3). 265-294.

Lucy, John. 1996. The scope of linguistic relativity: An analysis and review of empirical research. In John Gumperz \& Stephen Levinson (eds.), Rethinking linguistic relativity, 37-69. Cambridge: Cambridge University Press.

MacWhinney, Brian. 2000. The CHILDES project: Tools for analyzing talk. Hillsdale, NJ: Lawrence Erlbaum.

Moder, Carol Lynn \& Aida Martinovic-Zic (eds.). 2004. Discourse across languages and cultures. Amsterdam \& Philadelphia: John Benjamins.

Moss, Barbara. 2004. Teaching expository text structures through information trade book retellings. The Reading Teacher 57. 710-718.

Pavlenko, Aneta (ed.). 2011. Thinking and speaking in two languages (Bilingual education and bilingualism.) Clevedon: Multilingual Matters.

Pederson, Eric. 1995. Language as context, language as means: Spatial cognition and habitual language use. Cognitive Linguistics 6. 33-62.

Ragnarsdóttir, Hrafnhildur, Melina Aparaci, Dalila Cahana-Amitay, Janet van Hell \& Anne Viguié. 2002. Verbal structure and content in written narrative and expository texts. Written Language \& Literacy 5. 95-127.

Sahonenko, Natalja. 2004. Zeitkonzepte in Nacherzählungen. Eine kontrastive Studie zum Russischen und Deutschen. Heidelberg: University of Heidelberg Master's thesis.

Sledzka, Dorota. 2006. Zum Ausdruck der Temporalität im Deutschen und im Polnischen. Heidelberg: University of Heidelberg dissertation.

Slobin, Dan. 1987. Thinking for speaking. Proceedings of the thirteenth annual meeting of the Berkeley Linguistics Society. 435-444.

Slobin, Dan. 1991. Learning to think for speaking: Native language, cognition, and rhetorical style. Pragmatics 1. 7-26. 
Slobin, Dan. 1996. From "thought and language" to "thinking for speaking”. In John Gumperz \& Stephen Levinson (eds.), Rethinking linguistic relativity, 70-96. Cambridge: Cambridge University Press.

Smith, Carlota. 1991. The parameter of aspect. Dordrecht: Kluwer.

Smith, Carlota. 2003. Aspectual entities and tense in discourse. In Paula Kempchinsky \& Slaba Roumyana (eds.), The syntax, semantics and acquisition of aspect, 223-237. Amsterdam: Kluwer.

von Stutterheim, Christiane. 1997. Einige Prinzipien des Textaufbaus. Tübingen: Niemeyer.

von Stutterheim, Christiane \& Mary Carroll. 2006. The impact of grammatical temporal categories on ultimate attainment in L2 learning. In Heidi Byrnes, Heather Weger-Guntharp \& Katherine Sprang (eds.), Educating for advanced foreign language capacities, 40-53. Georgetown: Georgetown University Press.

von Stutterheim, Christiane \& Wolfgang Klein. 2002. Quaestio and I-perspectivation. In Carl Friedrich Graumann \& Werner Kallmeyer (eds.), Perspectivity and perspectivation in discourse, 56-88. Amsterdam \& Philadelphia: Benjamins.

Talmy, Leonard. 1985. Lexicalization patterns: Semantic structure in lexical forms. In Timothy Shopen (ed.), Language typology and syntactic description, vol. 3: Grammatical categories and the lexicon, 57-149. Cambridge: Cambridge University Press.

Talmy, Leonard. 1988. The relation of grammar to cognition. In Brygida Rudzka-Ostyn (ed.), Topics in cognitive linguistics, 165-205. Amsterdam \& Philadelphia: John Benjamins.

Talmy, Leonard. 1996. Fictive motion in language and 'ception'. In Paul Bloom, Mary Peterson, Lynn Nadel \& Merrill F. Garrett (eds.), Language and space, 211-276. Cambridge, MA: MIT Press.

Talmy, Leonard. 2000. Towards a cognitive semantics. Cambridge: MIT Press.

Tomita, Naoko. 2008. Der Informationsaufbau in Erzählungen. Eine sprachvergleichende Untersuchung des Japanischen, des Deutschen und des Englischen zum Einfluss von einzelsprachlichen Systemeigenschaften auf die makrostrukturelle Planung. Munich: Iudicium.

Toulmin, Stephen. 1958. The uses of argument. Cambridge: Cambridge University Press.

Weaver, Charles A. III \& Walter Kintsch. 1991. Expository text. In Rebecca Barr, Michael L. Kamil, Peter B. Mosenthal \& P. David Pearson (eds.), Handbook of reading research, Vol. 2, 230-254. New York: Longman.

Zifonun, Gisela, Ludger Hoffmann \& Bruno Strecker (eds.). 1997. Grammatik der deutschen Sprache. Berlin \& New York: De Gruyter. 
